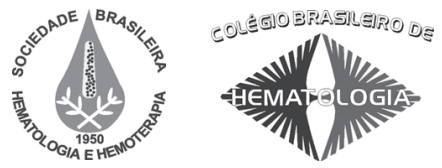

\title{
O cotidiano das famílias de crianças e adolescentes portadores de anemia falciforme
}

\section{The day-to-day life of families with children and adolescents with sickle cell anemia}

Tania M. R. Guimarães ${ }^{1}$

Wagner L. Miranda ${ }^{2}$

Márcia M. F. Tavares ${ }^{I}$

\begin{abstract}
A anemia falciforme $(A F)$ é a doença mais comum entre as hemoglobinopatias, caracterizada por uma mutação genética que compromete as funções das hemácias, desencadeando crises de vaso-oclusão e predisposições às infecções. O objetivo deste trabalho foi analisar o cotidiano das familias com filho portador de AF. Foi feito estudo descritivo, exploratório e qualitativo. O método utilizado foi a gravação de dez entrevistas semiestruturadas com os familiares de menores de 18 anos portadores de AF, atendidos em outubro de 2007 no Hemope. A seleção dos sujeitos foi residir e ter parentesco em primeiro grau do paciente. O critério de exclusão foi a criança apresentar risco de morte. O tamanho da amostra seguiu os critérios de saturação dos discursos de Mynaio. ${ }^{12}$ Na avaliação empregou-se a técnica de "Análise de Conteúdo" de Bardin. ${ }^{13}$ As falas obtidas foram transcritas integralmente e agrupadas de acordo com a semelhança, buscando os sentimentos relevantes que originaram códigos e temas: 1. Tema: Envolvimento da família (subtema: exclusividade da atenção; códigos: superproteção, abrindo mão de outros papéis, sobrecarga materna, aprendendo com a doença); 2. Tema: Impacto da doença (subtema: doença crônica afetando a família; códigos: não aceitação, temor da morte); 3. Tema: Enfrentando desafios (subtemas: redes de apoio, serviço de saúde; códigos: apoio espiritual, profissional e familiar; estrutura hospitalar). Verificamos dificuldades na aceitação da doença pela família e uma sobrecarga materna na realização dos cuidados. Os modelos assistenciais devem permitir que a família atue como coparticipante nos cuidados de forma a facilitar a adaptação do paciente à doença. Rev. Bras. Hematol. Hemoter. 2009;31(1):9-14.
\end{abstract}

Palavras-chave: Anemia falciforme; doença crônica;enfermagem pediátrica; família.

\section{Introdução}

A anemia falciforme como problema de Saúde Pública

O termo doença falciforme engloba um grupo de anemias hemolíticas hereditárias que têm em comum a presença de hemoglobina S dentro da hemácia. Representa a enfermidade hereditária mais prevalente no mundo. ${ }^{1}$
Segundo o Ministério da Saúde do Brasil, ${ }^{2}$ o gene pode ser encontrado em frequências de $2 \%$ a $6 \%$ nas regiões do país, aumentando para $6 \%$ a $10 \%$ na população afrodescendente brasileira. No Nordeste do Brasil, a prevalência do gene é de $3 \%$, chegando a 5,5\% no estado da Bahia. Em Pernambuco estima-se uma prevalência de 3,5\%, segundo estudo realizado em maternidades públicas do estado.

Neste grupo, destaca-se a anemia falciforme (AF), que apresenta importância clínica, hematológica, bioquímica,

${ }^{1}$ Enfermeira do Hemope. Professora Assistente da Faculdade de Enfermagem Nossa Senhora das Graças (FENSG) - UPE.

${ }^{2}$ Enfermeiro. Professor da Faculdade de Enfermagem de Belo Jardim (FAEB)-PE.

Faculdade de Enfermagem Nossa Senhora das Graças (FENSG) - Universidade de Pernambuco - Recife-PE.

Fundação de Hematologia e Hemoterapia de Pernambuco (Hemope) - Recife-PE

Correspondência: Tânia Maria Rocha Guimarães

Rua Teles Júnior, $n^{o}$. 155 - bl. A-apto.501 - Rosarinho

52050-040 - Recife-PE - Brasil

Email:tmrguimaraes@ig.com.br 
genética, antropológica e epidemiológica, entre outras, devido à sua morbidade e alto índice de mortalidade, por isso tem sido apontada como uma questão de saúde pública. A Organização Mundial da Saúde estima que, anualmente, nasçam no Brasil perto de 2.500 crianças com doença falciforme, das quais cerca de 1.900 têm $\mathrm{AF}^{3}$

\section{Aspectos fisiopatológicos}

A alteração molecular primária na $\mathrm{AF}$ é representada pela substituição de uma base no códon 6 do gene da globina beta, com a substituição de uma adenina por timina (GAG $\rightarrow$ GTG). Esta mutação resulta na permuta do resíduo glutamil pelo valil ( $\beta 6 \mathrm{Glu} \rightarrow \mathrm{Val}$ ) provocando a polimerização das moléculas dessa hemoglobina anormal $(\mathrm{HbS})$ quando desoxigenadas. ${ }^{4}$

As moléculas de $\mathrm{HbS}$ quando desoxigenadas se organizam em longos polímeros de filamentos duplos, que se associam em feixes rodeados de seis filamentos duplos de polímeros. Esses feixes de "cristais" dentro das hemácias determinam as deformações das células. A deformação mais conhecida é provocada por feixes de polímeros se organizando mais ou menos paralelamente, dando à hemácia uma forma alongada conhecida por "hemácia em foice"., 4

Os eventos citados constituem a base para o encurtamento da vida média dos eritrócitos, com consequente anemia hemolítica, e na oclusão da microcirculação com isquemia e o infarto tecidual, resultando em lesão orgânica crônica e em crises dolorosas agudas, que são as manifestações mais típicas das doenças falciformes. ${ }^{4,5,6}$

\section{Repercussões da doença crônica na família}

A família é uma instituição criada pelo homem em relação aos seus semelhantes e que assume variadas formas em situações e tempos diferentes, mas sua tarefa principal é "o cuidado e a proteção de seus membros". As relações que se estabelecem internamente entre os seus membros, ou externamente com a sociedade civil e o Estado, sofrem influências do contexto histórico em que está inserida. ${ }^{7}$ Portanto, é importante compreender o grupo familiar na complexa rede cultural e social que envolve, pois, sendo uma instituição baseada na troca de relações, tem para seus membros uma representação socialmente construída e que orienta a condução da sua dinâmica. Assim, as mudanças no ambiente familiar são por eles vividas de forma intensa ao interagirem entre si e com outros agentes sociais. ${ }^{8}$

Segundo Damião e Ângelo, ${ }^{9}$ doença crônica (DC) é definida como uma enfermidade incurável que: 1 . Afeta o funcionamento da pessoa por mais de três meses por ano; 2. Causa hospitalizações que, somadas, têm duração maior que um mês ao ano; 3 . Requer o uso de dispositivos permanentes de adaptação.

A DC apresenta gravidade variável, tendo como ca- racterística a instabilidade e reagudização periódica com exarcebação de seus sinais e sintomas. Portanto, as condições crônicas raramente são curadas, mas podem ser administradas com dedicação e esforço pelo indivíduo e sua família. ${ }^{10}$

O diagnóstico de uma DC é um choque para a família e desencadeia uma crise de adaptação. Portanto, as questões relacionadas ao enfrentamento da situação são importantes e devem ser exploradas para que a família possa ser compreendida em suas reais necessidades. A AF pode ser diagnosticada no nascimento ou na infância. Geralmente, os sintomas são observados após o sexto mês de vida. Independente do momento, a descoberta faz com que a criança e seus familiares tenham suas vidas bastante alteradas. ${ }^{11}$

Desse modo, por mais harmoniosa que seja a família, a crise é inevitável. Pois o nascimento de um filho com deficiência ou doença, ou o aparecimento de alguma condição excepcional, significa uma destruição de todas as esperanças e expectativas que haviam sido geradas em função dele. ${ }^{11}$

A vida da pessoa com filho portador de DC sofre mudanças irreversíveis, com as quais a pessoa interage. Além disso, as mudanças requerem administração constante da situação vivenciada. Portanto, as famílias devem encontrar o significado que a doença tem e determinar qual a percepção e os comportamentos relacionados com a situação, com a finalidade de manter uma vida prazerosa.

Neste estudo, conhecer a família, sua constituição, a relação de seus membros, o cotidiano, como reestruturam a vida familiar e participam do cuidado prestado é de fundamental importância para facilitar a adaptação em torno da condição crônica do filho. O objetivo geral foi analisar o cotidiano das famílias com filhos portadores de $\mathrm{AF}$ atendidos no Hospital da Fundação de Hematologia e Hemoterapia de Pernambuco, a fim de identificar a repercussão da condição crônica na dinâmica familiar.

\section{Casuística e Método}

O estudo foi realizado na Fundação de Hematologia e Hemoterapia de Pernambuco (Hemope), uma organização de caráter científico, educacional e assistencial vinculada à Secretaria de Saúde do Estado. Foi fundada em 1977 e se destaca como referência nacional no diagnóstico laboratorial e tratamento das patologias do sangue, atuando no desenvolvimento da medicina transfusional e no apoio aos serviços de transplante de órgãos.

Realizou-se um estudo descritivo, exploratório e qualitativo através da gravação de uma entrevista orientada por questionário semiestruturado, para os familiares de crianças e adolescentes portadores de AF, atendidos nos setores de SPA e na Unidade de Internação Pediátrica. Os critérios de inclusão dos sujeitos foram: a) Residir e ter parentesco em primeiro grau dos menores de 18 anos portado- 
res de AF; b) O paciente não estar em risco de morte durante a entrevista.

A coleta de informações foi realizada em outubro de 2006 após ter sido aprovada pelo Comitê de Ética e Pesquisa do Hemope (parecer $n^{\circ} 030 / 06$ ). Os entrevistados foram orientados do objetivo do estudo e sobre o Termo de Consentimento Livre e Esclarecido. O questionário foi submetido à validação interna através de um teste piloto, realizado em setembro de 2006.

O número de sujeitos que constituíram o tamanho da amostra foi determinado com base no critério de saturação expresso na repetição dos discursos, segundo Mynaio. ${ }^{12}$ A análise das entrevistas revelou a repetição das "falas" a partir da décima família.

Os conteúdos das entrevistas foram ordenados a partir da transcrição integral das gravações, preservando a originalidade. Na avaliação empregou-se a técnica de "Análise de Conteúdo" proposta por Bardin. ${ }^{13}$ As falas das entrevistas foram apresentadas com a seguinte legenda: $\mathrm{E}_{1}$ : Entrevista $1 ;(. .$.$) pausa; e ...recortes da mesma fala.$

Na primeira etapa selecionou-se o material de acordo com a semelhança dos relatos e, após, o conteúdo foi agrupado de acordo com semelhança dos sentimentos, originando códigos e subtemas que, após sua ordenação, possibilitaram a construção de quatro temas principais: "Envolvimento da família", "Impacto da doença", "Enfrentando desafios" e "Estrutura hospitalar".

\section{Discussão}

A partir da caracterização das crianças e adolescentes portadores de $\mathrm{AF}$ atendidos no Hemope, observamos que a maioria (nove) dos pacientes era do sexo feminino e apresentava idade entre 15 meses a 14 anos. Grande parte deles era procedente da região metropolitana do Recife. Verificamos que o número médio de internamentos foi de cinco/ano, demonstrando a importância do acompanhamento contínuo desses pacientes no ambulatório, como forma de prevenir o agravamento do quadro da doença.

Do total (dez) das famílias entrevistadas, sete possuíam pelo menos um irmão com traço falciforme. Algumas considerações sobre o caráter hereditário da doença já foram citadas no estudo, ${ }^{1,2,4}$ e nossos dados reforçam a necessidade de orientação dessas famílias quanto à possibilidade do nascimento de mais de um filho doente.

A maioria dos pais possuía entre 22 e 40 anos e apresentava oito anos de estudo, o que comprometeu a renda familiar, que variou entre um e dois salários mínimos. Das famílias entrevistadas, oito genitoras relataram não exercerem atividade fora do lar pela impossibilidade de sair para trabalhar, devido ao tempo dispensado no cuidado diário ao filho com doença crônica. Semelhantemente, sete mães responderam ser o principal responsável pelo cuidado em todas as situações.
De forma semelhante, Lins, ${ }^{14}$ no estudo realizado no Hemope sobre eventos mórbidos em crianças menores de 10 anos portadoras de doenças falciformes, no período de 1983 a 1996, verificou que $93 \%$ das famílias possuíam renda de até um salário mínimo, e 51\% tinham os pais desempregados, os quais sobreviviam da ajuda de parentes ou trabalhavam na economia informal.

Segundo Kikuchi, ${ }^{15}$ as famílias do paciente portador de $\mathrm{AF}$, por atingir frequentemente a população negra, em sua maioria, vivem em situação de pobreza e encontram dificuldades para vir ao hospital trazer a criança doente. Dentre essas famílias, alguns membros não sabem ler, e por isso há dificuldade no entendimento das orientações passadas pelos profissionais, no que diz a respeito aos cuidados com a saúde e as leis que garantem seus direitos. No Brasil, 85\% dos doentes falciformes adultos têm baixa escolaridade. Os poucos que conseguem ingressar no mercado de trabalho desenvolvem tarefas que requerem esforço físico, sendo incompatível com a doença.

\section{Tema 1: Envolvimento da família}

Considerando o fato de a AF ser uma síndrome que compromete diversos sistemas do corpo humano, é exigido um cuidado complexo e uma atenção contínua para a promoção de uma condição clínica estável da criança; para isso, é imprescindível o envolvimento da família, considerando as necessidades específicas individuais. A família convive, desde a fase do diagnóstico, com alterações de suas rotinas, voltando sua atenção para o filho doente.

\section{Código: Superproteção}

As crianças e adolescentes doentes, muitas vezes, determinam a exclusividade do cuidado materno por não permitirem que outras pessoas o façam. Do mesmo modo, a dependência é reforçada pelo vínculo mãe-filho. Para eles, terem a mãe cuidadora primária aumenta-lhes sua segurança e confiança, a ponto de haver superproteção pelo cuidador:

"A gente não deixa ela chorar muito... ela toma o choro... a gente dá o que ela quer pra ela não chorar ... alimentação dá o que ela quer." $\mathrm{E}_{1}$

" A gente trata ela de forma diferente como trata os outros, não que os outros recebam menos atenção, são crianças também como qualquer uma... mas com ela a gente ...eu não sei se é por conta desse problema que ela tem, mas ela é mais agarrada comigo e com a mãe do que eles... a mãe sempre tá cuidando, ajeitando." $\mathrm{E}_{7}$

Código: Outras funções maternas em decorrência da doença falciforme

Uma das mudanças decorrentes da doença crônica na familia refere-se ao trabalho das mães fora de casa. A mulher, 
que divide os papéis de mãe e trabalhadora, tem seu lado maternal e cuidador revelado de maneira intensa, abrindo mão de outros papéis para dedicar-se exclusivamente a seu filho doente. Sua atuação intensa e diária impede o exercício de atividades externas, porque a exigência de atenção integral impossibilita o desempenho de outras funções: ${ }^{16}$

"Eu passo o tempo todo me dedicando a ela, as vezes eu me esqueço de me cuidar, preciso me cuidar... dia e noite..., sem falar nas crises e quando ela tá nas crises a preocupação é dobrada." $\mathrm{E}_{2}$

"Dá o cuidado, só quem dá sou eu, por isso que eu perdi meu emprego, porque eu tava já ciente... Quando disse assim... depois de um ano que voltasse a trabalhar e foi visto no teste do pezinho... Eu vi que ele precisava de acompanhamento, eu preferi assim optar por dar mais atenção a ele, porque se eu colocasse alguém não ia ter cuidados que uma mãe tem, entendeu?" $\mathrm{E}_{5}$

\section{Código: Sobrecarga materna}

Os cuidados das crianças portadores de AF centralizam-se na figura materna, exigindo um tempo maior do que aquele dispensado às outras atividades. Essa dedicação mostra-se como uma dificuldade pelo fato da mulher culturalmente ter outras obrigações no núcleo familiar, especialmente nos casos em que não tem apoio, originando uma sobrecarga de atividades. ${ }^{17}$ É o que se observa nos seguintes relatos:

"Quem cuida dele sou eu porque não tem ninguém." $\mathrm{E}_{3}$

"Assim quem participa mais é eu, porque eu vivo mais diretamente com ela, meu marido trabalha fica o dia todo no trabalho, e quem convive mais sou eu, eu to tendo essas limitações agora por causa do bebê, mas antes da bebê...eu nem ia em casa... era direto ...passava dez dias... era dez dias, passava quinze dias... era quinze dias aqui." $\mathrm{E}_{4}$

"Ontem mesmo eu tive que socorrer ela sozinha, o pai dela mesmo não liga. Ninguém fica não, minha sogra foi pra Igreja e eu fico sozinha... o pai ganha o mundo." $\mathrm{E}_{10}$

Código: Aprendendo com a doença

A conjuntura social familiar sofreu mudanças políticas, sociais e econômicas, desde uma ação higienista a ações programáticas, em que a família foi convocada a ser coparticipante na promoção da saúde, e em que a assistência no lar e na comunidade se faz através da educação e de promoção dos hábitos salutares. ${ }^{18}$

O esclarecimento da doença para a família altera atitudes, minimizando a ansiedade, permitindo modificações nas relações conflitivas para um modelo mais harmonioso e terapêutico em relação à saúde das pessoas. Quando a famí- lia apresenta-se bem estruturada e a relação com a pessoa em tratamento é preservada, é possível obter bons resultados, mesmos em situações clínicas difíceis. ${ }^{19}$

"(...) fica com anemia grave, ela pode causar a morte do bebê, do doente... tem também os inchaços das pernas e dos pés... tem várias crises, fica sem andar, sem pegar as coisas, sentindo dor nas costas, sem melhorar a febre que é muito alta, sofre muita palidez de repente, tem as vacinas que tem que tomar, tem a alimentação que tem que ser correta sem queimar nenhuma, oferecer líquido ao doente." $\mathrm{E}_{2}$

"A anemia falciforme é uma doença genética, né? Que vem do pai e da mãe... a hemoglobina AS... se não me engano... esses tais traços causam a anemia que é uma hemoglobina em formato de foice né? Ai vem a dificuldade do sangue... o mesmo percurso que o sangue tem de passar.. dá dores nas articulações, incha os braços, as juntas." $\mathrm{E}_{4}$

\section{Tema 2: Impacto da doença}

Código: Não aceitação

Quando uma pessoa tem risco de vida ou doença terminal, ela vivencia cinco fases, que foram identificadas pela psiquiatra Elisabeth Küber-Ross, em meados de 1960. A primeira, a negação, o paciente e familiares não aceitam o diagnóstico. Depois, sentimentos de raiva e inconformismo em relação à doença por atingir um de seus filhos. Em seguida, a negociação ou barganha, onde há crédito no diagnóstico e na terapêutica. A quarta, interiorização, onde há o reconhecimento da doença e preparação para o pior, a morte. Por último, aceitação, onde todos estão preparados para enfrentar a morte. ${ }^{20}$ Conforme os relatos abaixo, as famílias apresentam sérias dificuldades em aceitar a doença:

"Eu até a data de hoje, pra ser sincera, não aceito essa doença, não vou falar eu aceito... porque não aceito....é um sofrimento incrivel, intenso, eu presenciei...tanto pra minha filha como pras crianças daqui.. pra mim particularmente como mãe... eu convivo porque tenho que conviver." $\mathrm{E}_{4}$

"Foi dificil pra mim aceitar, principalmente porque quem passa mais tempo nos hospitais é a mãe... é uma herança amarga...queria que minha filha fosse normal...Deus me perdoe, mas que eu tava falando com as vizinhas que eu não tô aguentando mais, porque desde de pequenininha que ela é assim. Ai eu tava dizendo assim...eu queria tirar a vida dela, depois a minha. ...,(começa a chorar) só isso mesmo." $\mathrm{E}_{8}$

Código: Temor da morte

As famílias de crianças e adolescentes portadores de AF apresentam necessidades emocionais, representadas pelo 
temor da morte, de forma semelhante a outras que possuem filhos com DC, permanecendo sempre em estado de alerta. Muitas vezes a criança adormece bem, podendo acordar com uma nova crise. Além disso, essas patologias demandam um cuidado diário diferenciado, gerando sofrimento emocional e desgaste físico intenso. Desse modo, a família passa por períodos de maior ou menor controle da doença, podendo não ter condições de manejar a situação, sentindo-se perdida e desesperançada: ${ }^{8}$

"Eu tenho mais facilidade de cuidar dela, o pai tem mais medo de perdê-la, ele tem muito medo que ela morra, mas também a experiência que já passei... eu tenho mais facilidade, eu enfrento tudo com mais cautela... sem medo, que ela tiver que passar eu estarei do lado dela, o pai tem mais dificuldade de lidar com aquilo...ele diz: olha que ela vai morrer." $\mathrm{E}_{2}$

"No começo foi muito difícil, meu marido não aceita, em tempo de crise, ele vem me culpar, foi você, você, a gente vê o desespero... depois a gente se controla, teve uma dia que ele veio me bater porque achou que eu provoquei a crise, depois ele se acalmou e esfriou a cabeça.... e viu que num era aquilo." $\mathrm{E}_{8}$

"Tem que reagir, dá uma de forte na hora. Quando ela vê que eu tô chorando, ela diz: chora não mamãe. Ela já foi na UTI, ela quando fica internada passa dois meses e assim eu fico 24 horas, uma horinha minha mãe fica com ela, por exemplo, de ontem pra hoje eu não dormi, sentada na cadeira balançando ela." $\mathrm{E}_{1}$

\section{Tema 3: Enfrentando desafios}

\section{Código: Apoio espiritual}

A cada dia se tem dado maior ênfase à natureza holística do cuidado de saúde. Portanto, é fundamental que a equipe de saúde respeite as crenças religiosas das famílias, permitindo a assistência espiritual dos paciente por líderes religiosos, para o desenvolvimento de meios que ajudem na superação das dificuldades encontradas no cuidado dos filhos:

"É porque tem aquilo mesmo. Eu digo assim.. Eu tenho fé em Deus que ele vai ficar bom. O pai e os irmãos também." $\mathrm{E}_{3}$

"Creio que Deus vai mandar alguém pra achar a cura pra essa doença como achou pro câncer há milagres." $\mathrm{E}_{4}$

\section{Código: Apoio profissional}

As famílias revelaram o quanto era importante receber o apoio da equipe de saúde, para enfrentar as situações cotidianas nos cuidados dos filhos. Portanto, os profissionais devem ampliar o foco da assistência oferecendo apoio de acordo com o contexto social em que vivem. Isso os tornará mais aptos a adquirir conhecimentos sobre a doença, melhorando o cuidado a ser prestado.

"Eu acho o atendimento excelente... ela tem plano de saúde, opto a vim pro Hemope... pra mim é igual aqui e no plano de saúde." $\mathrm{E}_{4}$

"É os profissionais.... eles procuram ajudar de todas as formas, não existe tratamento melhor no Recife do que na Fundação Hemope. Minha filha aqui é bem tratada, eu sou bem recebida. Às vezes não tem vaga.... Eles dão um jeitinho brasileiro...medicamento, vir aqui e não ter dipirona.... Os médicos e enfermeiras emprestam dinheiro pra eu comprar os medicamentos, chega o dia de eu pagar, eles não querem aceitar. Eu acho que aqui é tudo." $\mathrm{E}_{8}$

\section{Código: Apoio comunitário e familiar}

Semelhantemente, o estudo de Furtado e Lima ${ }^{21}$ sobre o cotidiano da família com filhos com fibrose cística, realizado em São Paulo, verificou a importância do apoio de outras famílias em situações semelhantes, e da comunidade, para o enfrentamento das situações inerentes às doenças crônicas. É a partir de redes de apoio comunitário e da troca de experiência que as famílias desenvolvem meios para enfrentar as dificuldades.

"A minha mãe sempre que pode tá comigo dando força, a família toda...até quando ela tá internada é meio mundo de gente preocupado(...) Eu procuro falar com os amigos, apesar que ela não toma sangue, eu procuro falar com os amigos pra doar sangue pra ela, hoje mesmo já veio 6 pessoas doar sangue pra ela." $\mathrm{E}_{8}$

"Minha mãe ta sempre junto né? A família de uma forma global tem o maior cuidado." $\mathrm{E}_{7}$

\section{Tema 4: Estrutura hospitalar}

Por qualidade em saúde entende-se a capacidade de oferecer um tratamento humano e personalizado ao cliente, procurando superar as expectativas quanto ao atendimento de suas necessidades explícitas e implícitas. Entretanto, os familiares revelaram haver sérios problemas estruturais, principalmente no Serviço de Pronto Atendimento, onde os pacientes são assistidos em situação de urgência, conforme os relatos abaixo:

"O que eu acho ruim aqui é a questão de leitos né! Não tem uma ela específica pra criança, fica criança e adulto tudo misturado. Eu acho que deveria melhorar isso aí... fora o estresse de ficar misturando adulto e criança... o leito...., os leitos tem pouco... o tempo todo a gente fica nas cadeiras o tempo todo.. até os pacientes adultos que também tem falciforme tão aí." $\mathrm{E}_{7}$ 
"...o pior daqui é a falta de leitos que tem, a gente chega aqui passa três quatro dias nessas cadeiras.." $\mathrm{E}_{9}$

\section{Conclusões}

Este estudo conclui que a AF afeta toda a família, sendo que a sobrecarga do cuidado recai sobre a figura materna. A mãe atende exclusivamente o filho, não desempenhando outras funções, o que provoca dificuldades no relacionamento familiar.

As redes de apoio aparecem como uma necessidade mais do que eminente, visto que as famílias revelam seus sentimentos e adquirem segurança na condução do tratamento. A interação das famílias com a equipe de saúde os auxilia frente a situações da doença, minimizando consequências negativas, facilitando a adaptação e a flexibilidade diante da doença crônica.

Os profissionais de saúde da Instituição pesquisada são reconhecidos pela excelente assistência prestada às crianças e adolescentes portadores de AF e pela vontade de ajudar as famílias.

\begin{abstract}
Sickle cell anemic is a common disorder among hemoglobinopatias, characterized by a genetic mutation which affects the function of the red blood cells, causing episodes of vaso-occlusion and predisposing sufferers to infections. This study aims at describing the day-to-day life of families with children and adolescents with sickle cell anemia. This was a descriptive, exploratory, qualitative investigation. Data collection was achieved by recording semi-structured interviews with relatives of ten under 18-year-old patients with sickle cell anemia attended in the Hemope Clinic in October 2006. The selection criteria of interviewees were that they lived with and were first degree relatives of the patient. The exclusion criterion was that the patient was at risk of death. The sample size followed the criteria of saturation discussed by Mynaio. The technique of "Analysis of Content" described by Bardin was used in the evaluation. The interviews were completely transcribed and grouped according to their similarities, searching for relevant feelings originating from codes and themes: 1. Theme: Involvement of the family (Exclusiveness of attention; codes: overprotection, relinquishing other roles, overload of mother, learning with the illness); 2: Theme: Impact of the illness (chronic illness affecting family; codes: nonacceptance, fear of death); 3. Theme: Facing challenges (Support networks, Healthcare services; codes: spiritual, professional, and family support; hospital structure). We verified difficulties in the acceptance of the illness by the family and the burden of the mother with necessary patient care. In conclusion, healthcare assistance models should allow the family to act as a co-participant in the care of the patient in order to facilitate the patient's adaptation to the disease. Rev. Bras. Hematol. Hemoter. 2009;31(1):9-14.
\end{abstract}

Key words: Sickle cell anemic; chronic disease; pediatric nursing; family.

\section{Referências Bibliográficas}

1. Yoong WC, Tuck SM. Menstrual pattern in women with sickle cell anaemia and its association with sickling crises. J Obstet Gynaecol. 2002;22(4):399-401.

2. Brasil. Ministério da Saúde. Política Nacional de Saúde da População Negra: Uma Questão de Equidade. Brasília. 2001. 14p.

3. Alvarez Filho F, Naoum PC, Moreira HW, Cruz R, Manzato AJ, Domingos CRB. Distribución geográfica, etária y racial delas hemoglobinas S en Brasil. Sangre. 1995;40:97-102.

4. Costa FF. Anemia falciforme. In: Zago MA, Pasquini R, Falcão RP. Hematologia: fundamentos e prática. Rio de Janeiro: Atheneu, 2001. 290-307p.

5. Zago MA, Pinto ACS. Fisiopatologia das doenças falciformes: da mutação genética à insuficiência de múltiplos órgãos. Rev. Bras. Hematol. e Hemoter. 2007;29(3):207-14.

6. Zago MA. Anemia falciforme e doenças falciformes. In: Brasil. Ministério da Saúde. Secretaria de Políticas de Saúde. Manual de doenças mais importantes, por razões étnicas, na população brasileira afrodescendente. Brasília: Ministério da Saúde, 2001. p.13-29.

7. Valencio GB, Inamoratto LV, Fronza P. O familiar do cuidador do idoso com Alzeheimer: uma avaliação da qualidade de vida e do estresse psicossocial. Faculdade de Serviço Social. Núcleo de Pesquisas em Demandas Políticas e Sociais. Rio Grande do Sul. 2004.

8. Glat R, Duque MAT. Convivendo com filhos especiais: o olhar paterno. 2003. Rio de Janeiro: Viveiros de Castro.

9. Damião EBC, Ângelo M. A experiência da família ao conviver com a doença crônica da criança. Rev. Esc. Enf. USP. 2001;35(1):66-71.

10. Torres WC. O conceito de morte em crianças portadores de doença crônica. Psicologia, teoria e pesquisa. 2002;18(2): p.221-229 $<$ http://www.scielo.br/pdf/ptp/v18n2/a12v18n2.pdf

11. Rocha HHG. Anemia falciforme. Rio de Janeiro: Ed Rubio, 2004.277p.

12. Minayo MC de S. O desafio do conhecimento: Pesquisa qualitativa em saúde. $4^{a}$ ed. São Paulo: Hucitec. Rio de Janeiro: Abrasco,1996.

13. Bardin L. Análise de Conteúdo. São Paulo: Lisboa Edições, 1977.

14. Lins M. Eventos mórbidos em crianças de 0 a 10 anos, com doença falciforme, cadastradas no Hemope, no período de 1983 a 1996. Recife: Hemope. 1996.

15. Kikuchi BA. Anemia falciforme: manual para agentes de educação e saúde: procedimentos básicos, pesquisa bibliográfica, projetos e relatório, publicações e trabalhos científicos. 6ª ed. São Paulo: Atlas, 2003.

16. Anders JC. A família na assistência à criança e ao adolescente submetidos ao transplante de medula óssea: fase pós-TMO. [Dissertação]. Ribeirão Preto (SP): Escola de Enfermagem de Ribeirão Preto/USP;1999.

17. Ângelo M. Com a família em tempos difíceis: uma perspectiva de enfermagem. [Tese]. São Paulo (SP): Escola de Enfermagem /USP;1997.

18. Miranda MIF, Ferriani MGC. Políticas públicas sociais para crianças e adolescentes. Goiânia, AB Editora, 2001.

19. Mendes EG. Uma agenda para a saúde. São Paulo: Hucitec, 2004. 299 p.

20. Kübler RE. Sobre a morte e o morrer: o que os doentes têm para ensinar a médicos, enfermeiros, religiosos e aos próprios parentes. $7^{\mathrm{a}}$ ed. São Paulo: Martins Fontes, 1997.

21. Furtado MCC, Lima RAG. O cotidiano da família com filhos portadores de fibrose cística: subsídios para a assistência de enfermagem pediátrica. Rev. Latino-Americana de Enfermagem. 2003:11(1):66-73.

Suporte financeiro: Manuscrito derivado de Monografia de Residência de Enfermagem em Hematologia e Hemoterapía com bolsa do MEC.

Avaliação: Editor e dois revisores externos

Conflito de interesse: não declarado

Recebido: 25/05/2008

Aceito após modificações: 19/11/2008 